\title{
Toluene and Acetone Detection on Sensors Based on YSZ Electrolyte and Semiconducting Metal Oxide Nanoparticles
}

\author{
Monireh kasalizadeh ${ }^{1}$, Yadollah Mortazavi ${ }^{2}$, Abasali Khodadadi ${ }^{2}$ \\ ${ }^{1}$ School of Chemical Engineering, College of Engineering, University of Tehran, Tehran, Iran \\ Email-Address: mortazav@ut.ac.ir \\ ${ }^{2}$ Nanoelectronics Centre of Excellence, University of Tehran, Tehran, Iran
}

\begin{abstract}
In this study potentiometric sensors based on yttria stabilized zirconia (YSZ) with semiconducting metal oxides (SMO) as sensing electrode materials in $\mathrm{Pt} / \mathrm{YSZ} /(\mathrm{Pt}+\mathrm{SMO})$ structure, were fabricated and applied to detect $100-1000 \mathrm{ppm}$ acetone and toluene in the temperature ranges of $350-500^{\circ} \mathrm{C}$. $1.0 \mathrm{wt} \% \mathrm{Pt} / \mathrm{SnO}_{2}, 1.0 \mathrm{wt} \% \mathrm{Pt} /\left(4.95 \mathrm{wt} \% \mathrm{CeO}_{2}+94.05 \mathrm{wt} \% \mathrm{SnO}_{2}\right)$ once with the same thickness and once with different thickness are used as sensing materials and denoted as sensors I, II and III respectively. The results reveal that the sensors' response to toluene with $\mathrm{CeO}_{2}$-dopants, are improved, whereas those for acetone are suppressed particularly at lower temperatures and concentrations. It is also shown that by increasing the thickness, the response to acetone and toluene increased. However, the extent of improvement was more pronounced for acetone.
\end{abstract}

Key words: Potentiometric sensors, YSZ, Semiconducting metal oxide, Acetone, Toluene, $\mathrm{SnO}_{2}$

\section{Introduction}

Among the various sensing techniques used to detect harmful gases, solid-state sensors are of practical interest due to their small size and ease of use. Zirconia-based electrochemical sensors tailored for oxygen, NOx, CO and hydrocarbon detection have been widely investigated and can be used in harsh environments and high temperatures as compared to the semiconductor-based sensors such as $\mathrm{SnO} 2$-based sensors [1].

A. Lari et al. [2] investigated the effects of semiconducting metal oxides such as $\mathrm{Ce} 0.75 \mathrm{Zr0} .25 \mathrm{O} 2$ on the performance of YSZbased oxygen sensors. Recently, there has been growing interest in detecting VOCs with the solid-state sensors due to the regulations and standards for indoor air quality. For instance, Masami Mori et al. [3] modified oxygen sensor with $\mathrm{SmFeO} 3$ catalytic layer as sensing electrode for detection of different VOCs. The effects of modification of Pt working electrode with $\mathrm{SmFeO} 3$ were examined on the sensitivity and selectivity to VOCs. In addition, the effect of this catalytic layer thickness, were investigated on the sensitivity and response/ recovery times. In this study potentiometric sensors based on YSZ with semiconducting metal oxides as sensing electrode materials, were fabricated and applied to detect acetone and toluene. Both sides of the sensors were exposed to the same gas atmosphere, alternatively air and gases in air, without using air reference.

\section{Experimental}

YSZ as electrolyte of the sensors, is an oxygen ion conducting electrolyte and is synthesized with co-pricipitation method. Semiconducting metal oxides used in this study is $\mathrm{SnO}_{2}$ and $\mathrm{SnO}_{2}$ doped with 5.0 wt $\% \mathrm{CeO}_{2}$ were prepared with sol-gel method and then both samples impregnated with $1.0 \mathrm{wt} \% \mathrm{Pt}$.

The morphology and the crystalline phase of the powders were characterized by using a field emission scanning electron microscope (FESEM) and X-ray diffraction (XRD), respectively. The average crystallite sizes were calculated from the broadening of XRD peaks, using Scherrer formula. Specific surface area of the samples was determined by nitrogen adsorption using a surface area analyzer and BET method.

\section{Results and discussion}

The XRD spectra of the powders are presented in Fig.1. As is evident there is no indication of $\mathrm{CeO}_{2}$, inferring that ceria is either amorphous and/or crystalline with very small crystallite size. Average crystallite size calculated from Sherrer 
equation, BET area, and particle size obtained from the BET data are presented in Table 1.

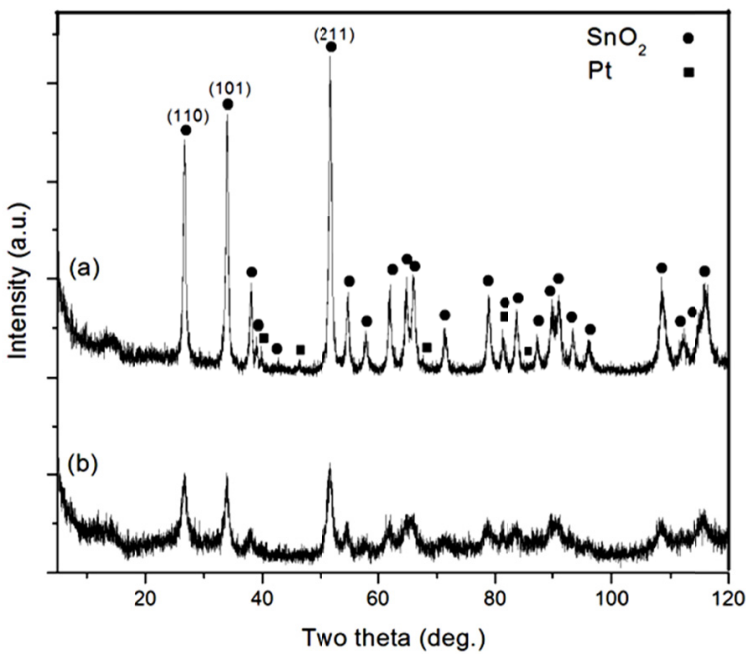

Fig. 1. XRD patterns of (a) $1.0 \mathrm{wt} \% \quad \mathrm{Pt} / \mathrm{SnO}_{2}$, and (b) $1.0 w t \% \mathrm{Pt} /\left(4.95 w t \% \mathrm{CeO}_{2}+94.05 w t \%\right.$ $\left.\mathrm{SnO}_{2}\right)$ calcined at $700^{\circ} \mathrm{C}$.

According to FE-SEM photographs (see Fig. 2) and Tab. 1, addition of semiconductor metal oxides as dopant to $\mathrm{SnO}_{2}$ led to an increase in surface area and a decrease in degree of agglomeration of particles and the crystallite size of $\mathrm{SnO}_{2}$.

Tab. 1: Average crystallite size approximated from $X R D, B E T$ area and particle size obtained from the $B E T$ data.

\begin{tabular}{|c|c|c|c|}
\hline Samples & $\begin{array}{c}\mathrm{d}_{\mathrm{XRD}} \\
(\mathrm{nm})\end{array}$ & $\begin{array}{c}\mathrm{BET} \\
\left(\mathrm{m}^{2} / \mathrm{gr}\right)\end{array}$ & $\begin{array}{c}\mathrm{d}_{\mathrm{BET}} \\
(\mathrm{nm})\end{array}$ \\
\hline $1.0 \mathrm{Pt} / \mathrm{SnO}_{2}$ & 18 & 10 & 86 \\
\hline $\begin{array}{c}1.0 \mathrm{wt} \% \mathrm{Pt} /(4.95 \\
\mathrm{wt} \% \mathrm{CeO}_{2}+94.05 \\
\left.\mathrm{wt} \% \mathrm{SnO}_{2}\right)\end{array}$ & 10 & 25 & 35 \\
\hline
\end{tabular}

The effect of dopant on the sensors' responses to $100 \mathrm{ppm}$ of acetone and toluene, in the temperature ranges of $350-500^{\circ} \mathrm{C}$ are presented in Fig. 3. The results reveal that the sensors' response to toluene with $\mathrm{CeO}_{2}$ dopants, are improved, whereas those for acetone are suppressed particularly at lower temperatures. The responses (EMF) and sensitivities at $400^{\circ} \mathrm{C}$ for each of the sensors are presented in Fig. 4 and Tab. 2, respectively. The sensitivity values were calculated from the slope of the linear fit of the EMF values verses $\log \left(\mathrm{C}_{\mathrm{VOC}}\right)$ (at the concentration range of 100 1000 ppm).

In Fig. 4 it is observed that both sensors have more sensitivity to acetone and with increasing
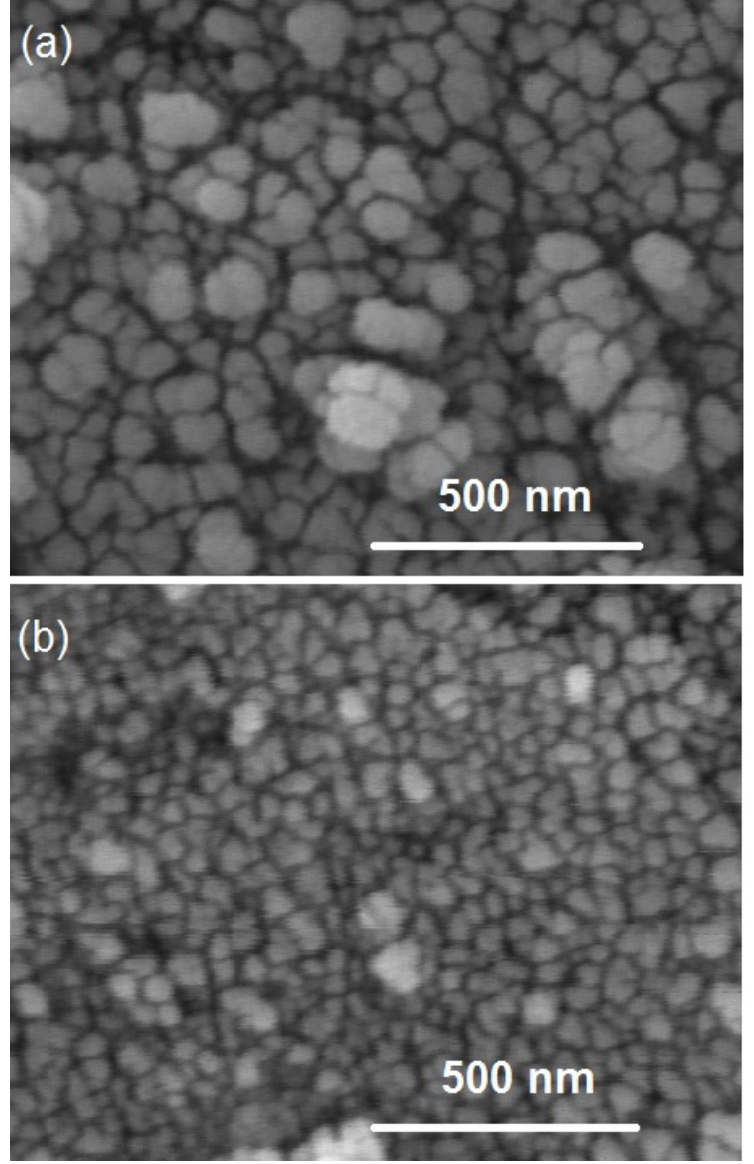

Fig. 2. FE-SEM photograghs of (a) $1.0 \mathrm{wt} \%$ $\mathrm{Pt} / \mathrm{SnO}_{2}$ and (b) $1.0 \mathrm{wt} \% \mathrm{Pt} /\left(4.95 \mathrm{wt} \% \quad \mathrm{CeO}_{2}+\right.$ $94.05 w t \% \mathrm{SnO}_{2}$ ) powders calcined at $700^{\circ} \mathrm{C}$.

concentration of toluene the responses of both sensors I and II are almost equal at concentration of $1000 \mathrm{ppm}$.

Furthermore, the effect of the catalyst layer thickness on performance of the sensor was investigated for the sensor with electrode containing $\mathrm{CeO}_{2}$ dopant (sensors II and III). The

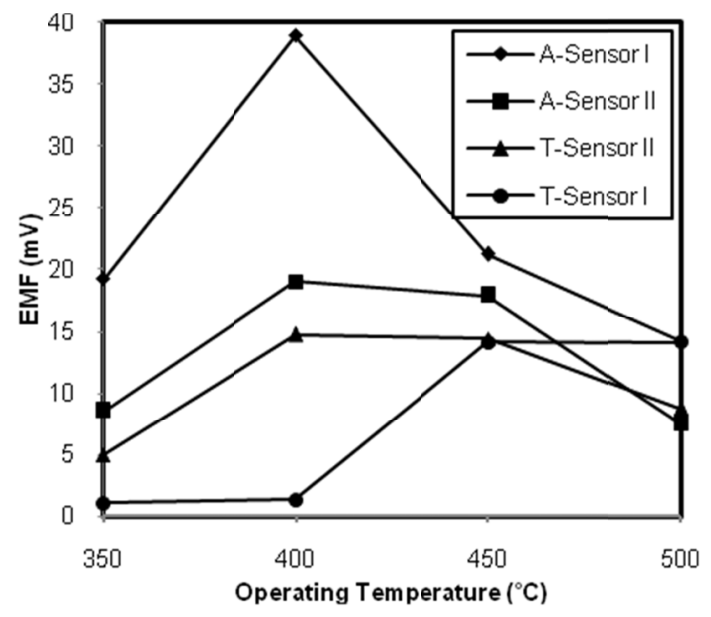

Fig. 3. Responses of sensor I and sensor II, to 100 ppm toluene $(T)$ and acetone $(A)$, as a function of operating temperature. 


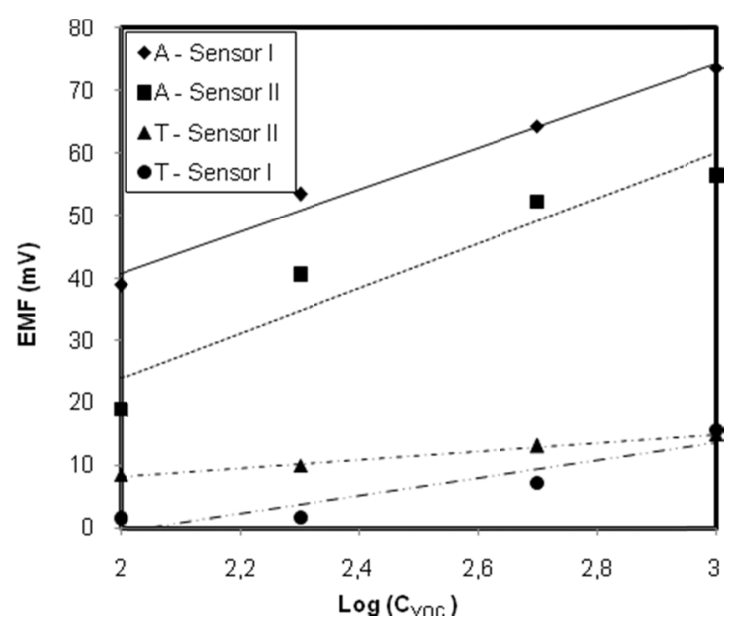

Fig. 4. EMF changes with the concentration of VOCs of the sensor I and sensor II, to toluene $(T)$ and acetone $(A)$ at $400^{\circ} \mathrm{C}$.

amount of 1.0 wt $\% \mathrm{Pt} /\left(4.95 \mathrm{wt} \% \mathrm{CeO}_{2}+94.05\right.$ wt $\% \quad \mathrm{SnO}_{2}$ ) powder used for fabrication of sensor III was twice of that used for sensor II. The performance of the sensors II and III is presented in Tab. 3.

Tab. 2: The sensitivity and $R^{2}$ for sensors I and II, at $400^{\circ} \mathrm{C}$ to toluene and acetone.

\begin{tabular}{|c|c|c|}
\hline VOC / Sensor No. & $\begin{array}{c}\text { Sensitivity } \\
\text { (mV/decade) }\end{array}$ & $\mathrm{R}^{2}$ \\
\hline to acetone / Sensor I & 33.6 & 0.984 \\
\hline to acetone / Sensor II & 36.1 & 0.903 \\
\hline to toluene / Sensor II & 6.7 & 0.994 \\
\hline to toluene / Sensor I & 14.3 & 0.878 \\
\hline
\end{tabular}

The results show that with increasing the thickness of the sensing electrode the EMF output is enhanced and its maximum shifts to higher temperatures. This may be attributed to the diffusion enhancement of VOCs through sensing electrode into the three phase boundary (TPB) sites. It is also observed the extent of improvement of EMF with the thickness of the sensing electrode is more pronounced for acetone. It seems that acetone diffuses more readily to TPB than toluene due to its smaller size.

Tab. 3: Response (EMF/mV) of the sensors II and III to $100 \mathrm{ppm}$ acetone and toluene at $350-500^{\circ} \mathrm{C}$

\begin{tabular}{|c|c|c|}
\hline $\mathrm{T} /{ }^{\circ} \mathrm{C}$ & $\begin{array}{c}\text { acetone } \\
\text { sensor II/sensor III }\end{array}$ & $\begin{array}{c}\text { toluene } \\
\text { sensor II/sensor III }\end{array}$ \\
\hline 350 & $8.5 / 8.4$ & $5 / 6$ \\
\hline 400 & $19 / 30$ & $14.7 / 15$ \\
\hline 450 & $17.9 / 33.1$ & $14.5 / 16.3$ \\
\hline 500 & $7.7 / 14.7$ & $10.1 / 11.13$ \\
\hline
\end{tabular}

\section{Conclusion}

The potentiometric YSZ based sensors using semiconducting metal oxides sensing electrodes, i.e. $1.0 \mathrm{wt} \% \mathrm{Pt} / \mathrm{SnO}_{2}$ and $1.0 \mathrm{wt} \%$ $\mathrm{Pt} /\left(4.95\right.$ wt $\left.\% \mathrm{CeO}_{2}+94.05 \mathrm{wt} \% \mathrm{SnO}_{2}\right)$, were fabricated and examined for detection ppm levels of acetone and toluene. The results reveal that the sensors' response to toluene with $\mathrm{CeO}_{2}$ dopants, are improved, whereas those for acetone are suppressed. Furthermore by increasing the catalyst layer thickness in the sensor with electrode containing $\mathrm{CeO}_{2}$ dopant, EMF output is enhanced and the extent of improvement was more pronounced for acetone.

\section{References}

[1] F. Menil, V. Coillard, C. Lucat, Sensors and Actuators B 67, 1-23 (2000); dio: 10.1016/S0925-4005(00)00401-9

[2] A. Lari, A. Khodadadi, Y. Mortazavi, Sensors and Actuators B 139, 361-368 (2009); doi: 10.1016/j.snb .2009.03.003

[3] M. Mori, H. Nishimura, Y'. Itagaki, Y. Sadaoka, Sensors and Actuators B 142, 141-146(2009); doi: 10.1016/j.snb.2009.07.026 